\title{
VIEWS AND REVIEWS
}

\section{David Oliver: Mixed sex wards may be inevitable}

\author{
David Oliver consultant in geriatrics and acute general medicine
}

Berkshire

The "humiliation" of "wards of shame" was how a section of the media reported NHS England's figures on mixed sex wards this spring. ${ }^{2}$ The figures showed 13700 "mixed sex breaches" in 2017-18. This was the highest level since 2010, when the collection of monthly mixed section accommodation "breaches" of "unjustified mixing in relation to sleeping accommodation" was introduced. ${ }^{3}$ Since 2012-13 NHS England has required in its operating framework that "all providers of NHS funded care are expected to eliminate mixed-sex accommodation, except where it is in the overall best interest of the patient." ${ }^{3}$

To put that number in context, over 14 million admissions were made to NHS hospitals in England in 2016-17. ${ }^{4}$ I don't seek to minimise the possible distress to patients staying in mixed sex bays or wards. Many-already sick, vulnerable, and in a dehumanising hospital environment-find mixed sex clinical areas undignified or threatening. ${ }^{5}$ The public reaction is what drove a Labour health secretary to make pledges on mixed sex accommodation in $2008^{6}$ and a Conservative one to repeat them in $2010 .^{7}$

But to me it seems a stellar achievement to have had only 13 700 official breaches in a health system with the fewest beds per 1000 people among all European and OECD nations, with midnight bed occupancy well over $90 \%$, with acute demand at record levels, and with performance worsening against emergency department waiting time targets. ${ }^{89}$

I think it's unwise for ministers to make such bold pledges on operational performance targets in an overstretched public service such as the NHS - especially pledges to "eliminate" phenomena such as mixed sex overnight accommodation and to make it some kind of "never" event. These ministers set themselves up to fail, while piling further pressure on frontline clinicians and managers.

Sometimes we simply have to make pragmatic decisions in the broader interest and then apologise for them

More broadly, campaigners, commentators, or regulators-none charged with delivering daily hands-on care-surely realise that bedded areas must be used flexibly. Every day, clinical and operational teams must balance a range and hierarchy of competing priorities, responsibilities, and accountabilities. Is it really worse to be admitted to a mixed sex bay than to face delays to an operation, be stranded in an overcrowded emergency department for hours, be denied access to specialist clinical areas, or be moved repeatedly from ward to ward? Do we ask patients and families that question? Do we explain that, even if the answer is yes, we must balance their individual preferences and worries with the (sometimes greater) needs of all patients requiring beds?

Sometimes we simply have to make pragmatic decisions in the broader interest and then apologise for them. It's easier to ask for forgiveness than permission. We can also take some common sense steps to reduce the indignity, distress, and loss of privacy that being on mixed sex wards can cause, such as those set out by the chief nursing officer in 2007-for instance, segregated toilets, use of bays, privacy screening, and better hospital clothing. ${ }^{10}$

I'd also say that we should be robust in defending staff involved in formal or informal complaints regarding admission to mixed sex areas, and we should be transparent and candid about the reasons. A universal service for the many will have occasions when the few-and in this case it is the very few-won't have what ought to be their reasonable expectations met.

Competing interests: See www.bmj.com/about-bmj/freelance-contributors/davidoliver.

Provenance and peer review: Commissioned; not externally peer reviewed.

Borland S. Number of patients enduring the humiliation of mixed-sex wards was at its worst level for seven years during the winter crisis. Mail 20 March 2018. https://www. dailymail.co.uk/health/article-5520833/NHS-patients-mixed-sex-wards-worst-level-sevenyears.html.

2 Gregory A. Humiliation of people forced to stay on mixed-sex wards soars by $50 \%$ under Theresa May. Mirror 21 July 2017. https://www.mirror.co.uk/news/politics/humiliationpeople-forced-stay-mixed-10849213.

3 NHS Digital. Mixed-sex accommodation (MSA). https://digital.nhs.uk/data-and-information/ data-collections-and-data-sets/data-collections/mixed-sex-accommodation-msa.

4 NHS Digital. Hospital admissions report published. 3 Oct 2017. https://digital.nhs.uk/newsand-events/news-archive/2017-news-archive/hospital-admissions-report-published.

5 NHS Confederation. Commission on improving dignity in care. 30 April 2014. https://www. nhsconfed.org/supporting-members/care-quality/key-initiatives/partnership-on-dignity-incare/commission-on-improving-dignity-in-care.

6 Government set to abolish "mixed-sex accommodation" on NHS wards. Evening Standard 1 May 2008. https://www.standard.co.uk/news/government-set-to-abolish-mixed-sexaccommodation-on-nhs-wards-6643915.html. 
7 Prince R. Andrew Lansley to announce end of mixed wards by year's end. Telegraph 15 Aug 2010. https://www.telegraph.co.uk/news/health/news/7946790/Andrew-Lansley-toannounce-end-of-mixed-wards-by-years-end.html.

8 Ewbank L. Hospital bed numbers - can the downward trend continue? King's Fund. 29 Sept 2017. https://www.kingsfund.org.uk/blog/2017/09/hospital-bed-numbers.

9 Anandaciva S, Jabbal J, Maguire D, Ward D. How is the NHS performing? June 2018 quarterly monitoring report. King's Fund. 10 July 2018. https://www.kingsfund.org.uk/ publications/how-nhs-performing-june-2018.
10 Improving patients' privacy and dignity on mixed-sex wards. Nurs Times 22 July 2007. https://www.nursingtimes.net/improving-patients-privacy-and-dignity-on-mixed-sex-wards/ 199234.article.

Published by the BMJ Publishing Group Limited. For permission to use (where not already granted under a licence) please go to http://group.bmj.com/group/rights-licensing/ permissions 